www.jmscr.igmpublication.org

Impact Factor (SJIF): 6.379

Index Copernicus Value: 71.58

ISSN (e)-2347-176x ISSN (p) 2455-0450

crossrefDOI: https://dx.doi.org/10.18535/jmscr/v6i7.126

Journal Of Medical Science And Clinical Research

IGM Publication

An Official Publication of IGM Publication

\title{
A Clinical and Radiographic Assessment of Periodontal Regeneration in Vital and Nonvital Teeth
}

\author{
Authors \\ Dr Maya S. Indurkar ${ }^{1}$, Dr Manjiree S.Awad ${ }^{2}$ \\ ${ }^{1}$ Prof. and HOD GDC and Hospital Aurangabad, India \\ ${ }^{2}$ PG Student, GDC and Hospital Aurangabad, India
}

\begin{abstract}
Introduction: Pulpal and periodontal diseases are main etiological factors of tooth mortality. Inter relationship between these two diseases is the topic of research. Less literature is available on the effect of endodontic treatment of periodontal tissue healing. The, present study is conducted to evaluate effect of regenerative periodontal therapy in vital and non-vital teeth.

Materials and Methods: 10 sites with intrabony defect requiring regenerative periodontal therapy divided into 2 groups, Group-I 5 sites with intrabony defect where tooth is nonvital and root canal treatment is completed. Group-II 5 sites with intrabony defect and tooth is vital. At baseline sites were measured for probing pocket depth (PPD), clinical attachment level (CAL) and radiographic bone defect depth. 6 month post operatively sites were measured for probing pocket depth (PPD), clinical attachment level (CAL) and radiographic bone fill. After phase I therapy, follow up was done at 6 weeks. Intrabony defect $\geq 5 \mathrm{~mm}$ clinically and $\geq 3 \mathrm{~mm}$ radiographically were included in the study. Regenerative periodontal therapy with DFDBA and chorion membrane was performed.

Result and Conclusion: In Group I the mean reduction in pocket depth from baseline to 6 months was $3.3 \pm 0.42$, gain in clinical attachment level was $3.6 \pm 0.4$ and amount of bone fill was $3.6 \pm 0.54$ which was statistically significant. In Group II the mean reduction in pocket depth from baseline to 6 months was $3.78 \pm 0.78$, gain in clinical attachment level was $1.9 \pm 0.3$ and the mean amount of bone fill was $2.8 \pm 0.57$ which was statistically significant. On intergroup comparison the mean reduction in PPD and gain in CAL were not statistically significant and the radiographic bone fill was statistically significant.
\end{abstract}

\section{Introduction}

Periodontitis is a disease of the periodontium characterized by clinical attachment loss and formation of osseous deformities, including furcation and intrabony defects. The intrabony defect is defined as pathologic sulcus in which the base of the pocket is apical to the alveolar bone crest. $^{1}$ The ultimate objective of periodontal therapy is to regenerate tissues lost as a consequence of periodontal disease. The most positive outcome of periodontal regeneration procedures in intrabony defect has been achieved with a combination of bone graft and guided tissue regeneration, this association is called as Combined Periodontal Regenerative Technique (CPRT). ${ }^{2,3}$ The interaction between the pulp and the periodontal apparatus and their effects on wound healing has not been clearly elucidated. 
Definitive conclusions could not be obtained regarding the regenerative potential of the attachment apparatus of endodontically treated teeth. The scanty literature and lack of comparative studies between periodontal regeneration in vital and non-vital teeth merits present study. The present study aimed to compare effect of Combined Periodontal Regenerative Technique in intrabony defects using DFDBA as a bone substitute and Chorion as a bioresorbable membrane in the treatment of vital and non-vital teeth.

\section{Materials and Methods}

10 sites with intrabony defect requiring regenerative periodontal therapy divided into 2 groups, Group-I 5 sites with intrabony defect where tooth was nonvital and root canal treatment was completed. Group-II 5 sites with intrabony defect and tooth was vital.

Exclusion criteria- Known systemic illness \&/ drug therapy that would interfere with wound healing, Pregnancy/lactation, smoking (or tobacco use in any other form), unacceptable oral hygiene after re-evaluation of phase I therapy.

At baseline sites were measured for probing pocket depth (PPD), clinical attachment level (CAL) and radiographic bone fill and 6 month post operatively sites were measured for probing pocket depth (PPD), clinical attachment level (CAL) and radiographic bone fill. After phase I therapy, follow up was performed after 6 weeks.
Intrabony defect $\geq 5 \mathrm{~mm}$ clinically and $\geq 3 \mathrm{~mm}$ radiographically were included in the study. Regenerative periodontal therapy with DFDBA and chorion membrane was performed.

\section{Surgical procedures}

All the selected patients, following an initial examination, were subjected to phase I periodontal therapy and were given detailed instructions for plaque control measures. The non vital teeth were endodontically treated. The patients were subjected to surgical procedure 4-6 weeks after phase I therapy. A full thickness mucoperiosteal flap was reflected using the periosteal elevator. After reflection of the flap and exposure of osseous defect, thorough surgical debridement of both soft and hard tissues was done using curettes. The surgical site was irrigated with normal saline. In both the vital and nonvital teeth groups, 2-3 walled osseous defects were filled with DFDBA and covered with chorion membrane. The mucoperiosteal flaps were repositioned and secured in place with 4-0 black braided silk suture. Interrupted sutures were placed to obtain primary closure of the interdental papilla and the area was protected with non eugenol dressing (coe-Pack). All the patients were prescribed with analgesics and antibiotics. Post operative instructions were given to all the patients and After 10 days following surgery, the dressing and sutures were removed.

\section{Results}

Table 1 Showing clinical comparison of mean values of probing pocket depth (PPD), clinical attachment level (CAL), at baseline and 6month postoperatively in group I and group II

\begin{tabular}{|l|c|c|c|c|c|c|}
\hline & \multicolumn{3}{|c|}{ Group I } & \multicolumn{3}{c|}{ Group II } \\
\cline { 2 - 7 } & At baseline & 6month & P value & At baseline & 6 month & P value \\
\hline PPD & $8.9 \pm 0.7$ & $3.3 \pm 0.42$ & $<0.0001$ & $7.2 \pm 0.7$ & $3.78 \pm 0.78$ & $<0.0001$ \\
\hline CAL & $7.9 \pm 0.7$ & $4.34 \pm 0.32$ & $<0.0001$ & $6.2 \pm 0.7$ & $4.3 \pm 0.44$ & $<0.0001$ \\
\hline
\end{tabular}

Table 1 shows reduction in PPD, gain in CAL from baseline to 6 months in Group I and Group II which is statistically significant. 
Table 2 Showing comparison of radiographic defect depth (RDD) at baseline \& 6 month postoperatively, in Group I and Group II.

\begin{tabular}{|l|c|c|}
\hline & Group I & Group II \\
\hline RDD at baseline & $6.2 \pm 0.83$ & $6 \pm 0.79$ \\
\hline RDD at 6month & $2.6 \pm 0.54$ & $3.2 \pm 0.44$ \\
\hline Amount of bone fill at 6month & $3.6 \pm 0.54$ & $2.8 \pm 0.57$ \\
\hline
\end{tabular}

Table 2 shows that the amount of bone fill was statistically significant in Group I and Group II. On intergroup comparison amount of bone fill was more in Group I because RDD at baseline was more compared to Group II.

\section{Discussion}

In a clinical study done by Vandana et.al ${ }^{4} 16$ intrabony defects in nonvital and vital teeth were treated by regenerative periodontal therapy. Results showed that there is reduction in PPD, gain in CAL in both groups \& on intergroup comparison difference was nonsignificant. In the present study there is reduction in PPD, gain in CAL, in vital and novital groups and statistically there was no difference. Morris ${ }^{5}$, using human teeth with nonvital pulps was unable to demonstrate cementogenesis on dentin of endodontically obturated teeth. The work of Bjorn $^{6,7}$, Diem ${ }^{8}$ and Mitsis ${ }^{9}$ indicate that endodontically obturated teeth should respond to periodontal therapy as do the vital teeth. Dunlap et $\mathrm{al}^{10}$ indicated that the planed root surfaces of the endodontically obturated teeth were compatible with fibroblast growth in the in vitro study. No difference in growth was noted on the root-planed surfaces of vital teeth as compared to the rootplaned endodontically obturated teeth. In this study, the endodontic treatment in nonvital teeth preceeded periodontal surgery to minimize the penetration toxic substances from the pulp to the periodontal area. This is in accordance with the recommendation by Prichard ${ }^{11}$, who suggested debridement and medication of the canals before intrabony surgery. The sample size of the present study does not allow us to derive definitive conclusions and further studies are required on larger sample size.

\section{Conclusion}

Regenerative periodontal therapy performed in intrabony defects of vital and nonvital teeth showed reduction in PPD, gain in CAL and radiographic bone fill from baseline to 6 months. On intergroup comparison there was no statistically significant difference between vital and nonvital group.

\section{References}

1. Goldman HM, Cohen DW. The infrabony pocket: Classification and treatment. J Periodontol 1957:29:272-291.

2. McClain PK, Schallhorn RG. Long-term assessment of combined osseous composite grafting, root conditioning, and guided tissue regeneration. Int $\mathbf{J}$ Periodontics Restorative Dent 1993;13:9-27.

3. Guillemin MR, Mellonig JT, Brunsvold MA. Healing in periodontal defects treated by decalcified freeze-dried bone allografts in combination with ePTFE membranes (I). Clinical and scanning electron microscope analysis. J Clin Periodontol 1993;20:528-36.

4. Vandana $\mathrm{KL}^{*}$ Vanda KV Periodontal regeneration in vital and nonvital teeth - A clinical study journal of endodontology vol. 152003

5. Morris ML. Healing of human periodontal tissues following surgical detachment and extirpation of vital pulp. J Periodontol. 1960; 3:23.

6. Bjorn H. Experimental studies on reattachment. Dent Pract Dent Rec. 1961; 11 :

7. Bjorn H., Hollender L. and Lindhe J. Trissue regeneration in patients with 
periodontal disease Odontol Revy., 1965; 16:317.

8. Diem C, Bowers G, Ferrigno P and Fedi P. Regeneration of the attachment apparatus on pulpless teeth denuded of cementum in the rhesus monkey. J Periodontol. 1974;45: 18.

9. Mitsis FJ. Flap operation technique for the treatment of certain endodontic and periodontal problem. $\mathrm{J} \mathrm{Br}$ Endod Soc. 1970;4:6.

10. Dunlap RM, Grag JC, Turner WL et al. In vitro growth of human gingival fibroblasts on root surfaces of endodontically treated teeth. J Periodontol 1981; 52 :140-142.

11. Prichard JF. Advanced periodontal disease, surgical and prosthetic management, 2nd Edn., Phiadelphia, W.B.

Saunders 